\title{
Acceptance of Anthropomorphic Technology: A Literature Review
}

\author{
Samia Cornelius \\ Baylor University \\ samia_cornelius1@baylor.edu
}

\author{
Dorothy Leidner \\ Baylor University \\ dorothy_leidner@baylor.edu
}

\begin{abstract}
Anthropomorphic Technology (AT) is technology that is human-like in design and motivates anthropomorphism. Anthropomorphism is the attribution of human-like characteristics to nonhuman objects. Extant research informs user responses of familiarity and acceptance to AT, but also withdrawal from and rejection of AT. There is little integration of research on this topic. We examine and synthesize studies on user responses to AT published in leading IS journals. We identify kinds of anthropomorphic design and dimensions, and find that although most research demonstrates a positive influence of humanlike design on user response, many factors can moderate this effect. We recognize these factors and propose directions for future research.
\end{abstract}

\section{Introduction}

Acceptance of technology is an important topic of study in Information Systems, and as the technology evolves and develops to feature new design, the topic continues to attract renewed attention. One evolution stream is the incorporation of human-likeness in technology. Much of today's technology either looks or behaves like human beings. While figures suggest that human-like technology is increasingly becoming popular $[52,40]$, research also suggests that humanlikeness in machines may not be universally accepted [33].

Human-likeness in technology is the existence of human-like physical characteristics, behavioral and/or emotional intelligence, functions, and/or roles in machines. Incorporating human-like cues in machines motivates social responses from users, leading to familiarity and acceptance [36]. Acceptance of human-like machines is credited to the attribution of human-likeness or human-like characteristics to machines by the user [14]. The user is essentially the consumer who uses the technology to fulfill a personal or professional goal. Attribution of humanlike characteristics to machines is called anthropomorphism, and technology that possesses design features that motivate anthropomorphism can be referred to as anthropomorphic technology (AT) [14].

Anthropomorphism does not always lead to the acceptance of AT. Some research highlights the disadvantages of human-like design. The automation bias literature, for example, explains that machines are associated with rationality, objectivity, reliability, and efficiency [34]. Such expectations are lowered when machines are made human-like in design. As a result, the characteristics initially associated with the machines are confused with human-like appearance and function [46, 12, 34]. Based on the mismatch between their expectation and reality, people develop an attitude of distrust in AT and refrain from accepting or using it [46]. Similarly, the uncanny valley hypothesis by Mori [33] explains that technology that reaches a certain threshold of being almost but not fully human-like can elicit feelings of eeriness. Feelings of eeriness can make people uncomfortable and draw them away from the use and acceptance of the technology [33].

Developers and researchers alike seem to be confused about the user's reaction to the incorporation of human-likeness in technology. Experimentation is time-consuming and costly and has produced positive, negative, and nonsignificant results. There is little integration within the literature that can provide a guide to anthropomorphic design, the process that leads to user response, and/or the factors that moderate responses to AT. With this paper, we take a step towards the theoretical integration of insights by reviewing and analyzing studies related to anthropomorphic design in the field of Information Systems (IS). We present a literature review that categorizes and presents extant literature to understand the use and influence of AT better. We also identify variables that can moderate user response to AT. Finally, we highlight future research directions based on findings from extant literature.

The following research questions guide the literature review: (1) How do users respond to AT? and (2) What influences their response? Much of the 
published research on anthropomorphism and humanlike technology presents design as the center of analysis. Researchers try to find the effectiveness of human-like design for acceptance of technology by experimenting with a variety of design features. User responses are seen to be "good" (favorable/positive) and "bad" (unfavorable/negative/nonsignificant). These include user attitudes and/or behaviors that are beneficial or damaging to the personal/professional objectives, respectively. The Computers As Social Actors paradigm (CASA), theories on cognition and social response, and literature on anthropomorphism, are the dominant theoretical perspectives that are used to explain user response to AT.

The remainder of the manuscript is structured as follows. The next section of the paper presents an overview of anthropomorphism and anthropomorphic technology to guide the analysis of the studies. Section 3 presents the methodology, followed by the analysis of selected literature in section 4. Section 5 provides a discussion on the findings and future research directions. The paper ends with a summary in Section 6.

\section{Anthropomorphism and Anthropomorphic Technology}

Anthropomorphism is derived from the Greek words anthropos (human) and morphe (shape or form). It is the human tendency to attribute human characteristics to inanimate objects, animals, and other nonhuman entities [21, 50, 14]. Human-like attribution is based on prior knowledge acquired through observation of, and interaction with, other human beings, and is carried out to understand the world in a better way [21], to build social connections [35], and to enhance feelings of belonging [3].

Anthropomorphism is referred to as a chronic feature [21], an innate human tendency [14], and an inductive reasoning process that comprises of the acquisition, activation, and application of knowledge to a target $[22,14]$. It is recognized as mindless and mindful [26], where mindless anthropomorphism is a reflexive human response to nonhuman objects [26], and mindful anthropomorphism is an inductive reasoning process [22].

The tendency to anthropomorphize can vary from person to person. Variation in the likelihood to anthropomorphize is explained with the help of dispositional, situational, developmental, and cultural factors [14]. Disposition refers to the personality of an individual, situation refers to the transitory aspects of the environment that may change the accessibility of knowledge or the desire to understand or connect, and developmental and cultural variables refer to the changes in development or culture over time and how they influence people's tendency to anthropomorphize [14]. Human-like design in technology is considered a situational catalyst that enables the accessibility of human-like knowledge representations in the brain due to the perceived similarity between human beings and technology design $[14,53]$. In other words, human-like technology facilitates anthropomorphism and can be called Anthropomorphic Technology.

Anthropomorphic Technology (AT) can be human-like in form or function [13]. Human-like form is the physical embodiment of the machine and can be quite static and consistent [13]. It is the basic integration or employment of "humanness" in design [13] and is and interpreted as "human-like" by observation. Human-like form includes features like movement, shape, gesture, body, and/or appearance of the machine. Human-like function refers to the behavioral characteristics of machines and manifests how people think and behave with other human beings. It is visible in the way the machine thinks and interacts [13]. Human-like function can be incorporated in intelligence, natural language processing, conversational ability, interactivity, and purpose of technology. Together human-like form and function can facilitate anthropomorphism [14, 53].

AT is associated with familiarity and acceptance $[37,36]$ as well as issues of unpredictability, vagueness, and distrust $[48,34,33]$. The literature is divided and scattered. Besides, changing user preferences, technology demands, technological advancements, and a strong focus on technology design has made it difficult for designers to anticipate user response to new human-like design advancements in technology [13]. Future research demands the integration of extant studies. This review helps compile extant research in the field of Information Systems (IS) to explore the kinds of AT studied in the past and respective user responses. The theoretical perspectives used to explain user response are also discussed, and moderators that determine variation in response are identified.

\section{Methodology}

We follow the guidelines provided by Webster and Watson [55] to develop the literature review. The focus of the review includes studies that are published in (1) The Senior Scholar's Basket of Eight journals in IS, including European Journal of Information Systems (EJIS), Information Systems Journal (ISJ), Information Systems Research (ISR), Journal of the Association of Information Systems (JAIS), Journal of Information Technology (JIT), Journal of Management Information Systems (JMIS), Journal of 
Strategic Information Systems (JSIS), and Management Information Systems Quarterly (MISQ), and (2) Special Interest Group Human-Computer Interaction (HCI), including, AIS Transactions on Human-Computer Interaction (AIS THCI), ACM Transactions on Computer-Human Interaction (ACM TOCHI), International Journal of Human-Computer Studies (IJHCS), Human-Computer Interaction (HCI), and Computers in Human Behavior (CHB). These journals are chosen for their quality (The Senior Scholar's Basket of Eight journals in IS) and relevance (HCI) to the topic [51]. We set the scope of the review to include studies using anthropomorphism in technology as the main construct that either act as an intervention to influence outcome variables or is studied as a social attribution process. Outcome variables are not screened for context.

A search was run on the keywords "anthropomorphism," "anthropomorphic," and "anthropo." Articles were searched in the respective journal databases as well as Springer, Wiley Online Library, Informs, AIS Library, Taylor and Francis Online, Science Direct, JSTOR, and ACM Digital Library databases. Articles that included the keyword(s) in the title or abstract were shortlisted. The abstracts of all articles were then read to assess appropriateness for the review's scope. The Senior Scholar's Basket of Eight journals in IS yielded only 4 articles, out of which 1 was a debate/perspective piece. In the Special Interest Group, HCI, we found 42 articles discussing anthropomorphism, out of which 11 were excluded for not being intervention studies. A backward and forward search on Web of Science was undertaken to find more studies in The Senior Scholar's Basket of Eight journals in IS. The search yielded 3 more relevant articles. In total, 37 articles, published from 1998 to 2019, were chosen to be reviewed for the study.

\section{Analysis}

In the first step of the analysis, we examine humanlike cues in anthropomorphic design and the measurement variables used to reflect the acceptance of AT. Second, we explore the effect of human-like technology intervention on user response and factors that may lead to variations in the same. Responses help us identify ways in which people anthropomorphize AT. Finally, we detail theoretical perspectives used to explain user response to AT.

\subsection{Anthropomorphic Design}

AT can possess design cues of anthropomorphic form or function [13] that act as the situational catalyst for anthropomorphism [14]. About 70 percent of the studies implement both form and function in design. Only 4 studies incorporate form alone, and 7 incorporate just human-like function in technology design.

Anthropomorphic form refers to human-like characteristics that make up the physical embodiment of the machine [13]. Several researchers deploy animated agents on digital interfaces to motivate anthropomorphism and/or related responses [1, 5, 23, $56,25]$. Avatars and buddy icons are used to encourage interaction [38, 30, 24, 17]. Researchers experiment with face shape and smile in smart home assistants and robots [4, 6, 32], and gestures, postures, and facial expressions in interface agents $[9,20,26$, $31,41,43]$ to determine the effect on social attribution. Agility in robots and/or agents is also used to motivate anthropomorphism. For example, MacDorman [31] uses body movement in an online doctor-patient consultation context; Mara and Appel [32] use robot head tilts; Yuan and Dennis [56] incorporate jumping, clapping, and waving of hands is seen in online product displays; Shiban et al. [47] use hand movements along with face gestures in a humanlike digital tutor; Castro-González Admoni, and Scassellati [7] and Zhang et al. [57] use full and smooth body movements in robots. Sometimes, anthropomorphic form is incorporated in the appearance of a social agent. For example, researchers design digital agents to appear like doctors [31] health advisors [15] and tour guides [18]. Similarly, researchers embed gender [39, 30, 10, 26, 9, 47], ethnicity [42, 30, 9], age [44, 9, 47], and attractiveness $[47,44]$ to make digital agents appear like human beings.

Anthropomorphic function refers to the behavioral characteristics of the machines. It is a manifestation of how people think and behave with other human beings, and is visible in the way the machine thinks (intelligence) and interacts (behaves) [13]. Common examples include intelligence in conversation with regards to interactivity, responsiveness, and contingency $[15,23,18,19,26,8]$, and machines' ability to act with emotion [11]. Intelligent agents can communicate in a variety of words, message styles, and tones in both verbal and written communication to facilitate the attribution of human-like characteristics to a machine $[1,15,23,28,2,5,9,11$, 18, 41, 45, 57]. Language is sometimes complemented by the ability to speak and have a voice to enhance anthropomorphic function [31, 5, 41, $1,8,15,44]$. The purpose or task expected of the technology is also associated with its function. Human-like tasks such as those of help [9, 41, 42], assistance [1], mentoring [44, 57], and advice [15] 
add to anthropomorphic function for design. A table summarizing anthropomorphic technology, design cues, key contructs, and user responses for each paper included in the review can be made available on request.

\subsection{Anthropomorphism-related Constructs and User Response}

This paper highlights acceptance of AT as the focus of the review, however many variables are used as constructs that define or lead to acceptance. For example, anthropomorphism leads to understanding and relationship building, both of which facilitate acceptance of technology [14].

We find that, in general, human-like design has a positive effect on anthropomorphism and other anthropomorphism-related constructs and characteristics. Technology humanness in design leads to an increase in anthropomorphism [2, 32, 26, $38,57]$ resulting in favorable user responses of social presence [2, 38] and credibility judgments [26]. Studies that do not directly measure anthropomorphism show positive results associated with utility, usage, and usefulness [5, 44, 41, 42], productivity [15], competency [20], efficiency [24], information disclosure [45], and perceptual bandwidth [49]. Researchers also find users to develop an emotional connection [2], engagement [6], altruistic behavior [10], collaboration [30], interactivity [39], identification [38], trust [9], and social presence [42] as a result of interacting with AT.

It is hard to say whether form or function or both are important in supporting positive outcomes. Extant research presents mixed results. Out of the 37 studies reviewed, 49 percent present a positive influence of form on outcome variables. 30 percent provide a positive influence of function, and only 8 percent explain the positive influence of having both form and function design characteristics in technology.

Anthropomorphic form is associated with an increase in utility [5, 41, 42, 44], forming first impressions [6], reducing strain from privacy invasion [4], boosting perceived animacy [7], increasing credibility [9], supporting human agency [18], making positive evaluations [19], and supporting social responses [20]. Form supports social structuring [30], enjoyment and persuasion $[31,41]$, and similarity to self [38]. It also supports self-awareness [45] and selfefficacy [44]. Overall, it enhances social presence [41, 42], human-likeness [32], and anthropomorphism [39, 56].

Anthropomorphic function on the other hand leads to positive evaluations of social presence [2, 45], engagement [6], human-likeness [18, 26], human-like trust [27], performance [28, 26], perceptual bandwidth [49], and anthropomorphism [57]. Function also supports the user's emotional behavior towards machines [15] and influences perceptions of artifact personality type [1]. Function, when present in addition to form, is associated with an increase in communication efficiency and satisfaction [24], human-likeness [26], and interest [47].

Interaction with AT also results in adverse outcomes. Anthropomorphic form can lead to deception [17] and a decrease in collaboration [43]. Anthropomorphic function is associated with an increase in strain [4], artificiality, dominance, and intimidation [15], as well as lonely and preoccupied behaviors [54]. Form incorporated in addition to function has led to feelings of eeriness and discomfort $[7,25]$, as well as classification difficulty of humans versus machines [25]. Both form and function separately and together can sometimes be nonsignificant in determining change in user response to AT $[8,9,10,11,23,24,26,28,45,47,56]$. Table 1 presents a summary of user responses to anthropomorphic design.

Table 1. Summary of user responses to anthropomorphic design

\begin{tabular}{|c|c|c|c|}
\hline \multicolumn{4}{|c|}{ Anthropomorphic Design } \\
\hline \multicolumn{2}{|c|}{ Form } & \multicolumn{2}{|c|}{ Function } \\
\hline $\begin{array}{r}\text { Favorable } \\
18 \text { studies } \\
\end{array}$ & $\begin{array}{c}\text { Unfavorable } \\
6 \text { studies } \\
\end{array}$ & $\begin{array}{c}\text { Favorable } \\
11 \text { studies }\end{array}$ & $\begin{array}{c}\text { Unfavorable } \\
9 \text { studies }\end{array}$ \\
\hline $\begin{array}{l}\text { - } \text { Reduces strain [4] } \\
\text { - Increases utility [5, 41, 42, } \\
\text { 44] } \\
\text { - Influences first } \\
\text { impressions [6] } \\
\text { - Increases animacy [7] } \\
\text { - Increases credibility [9] } \\
\text { - Increases human agency } \\
\text { [18, 32, 38] } \\
\text { - Increases positive } \\
\text { evaluations [19] }\end{array}$ & $\begin{array}{l}\text { - No effect of additional } \\
\text { features on credibility [9] } \\
\text { - No effect on behavior [10] } \\
\text { - Increases deceptive } \\
\text { behavior [17] } \\
\text { - No effect on credibility } \\
\text { judgements [26] } \\
\text { - Decreases identification } \\
\text { [38] } \\
\text { - Decreases collaboration } \\
\text { [43] }\end{array}$ & $\begin{array}{l}\text { - Influences perceptions of } \\
\text { technology personality [1] } \\
\text { - Increases social presence } \\
\text { [2, 45] } \\
\text { - Increases engagement [6] } \\
\text { - Increases human agency } \\
\text { [15] } \\
\text { - Increases human-likeness } \\
\text { - } \text { Builds human-like trust } \\
\text { [27] }\end{array}$ & $\begin{array}{l}\text { - Increases strain [4] } \\
\text { - Decreases sociability [5] } \\
\text { - No effect on linguistic } \\
\text { alignment [8] } \\
\text { - No effect on feedback [11] } \\
\text { - Enhances artificiality, and } \\
\text { dominating and } \\
\text { intimidating behaviors } \\
\text { [15] } \\
\text { - No effect on social } \\
\text { responses [28] }\end{array}$ \\
\hline
\end{tabular}




\begin{tabular}{|c|c|c|c|}
\hline $\begin{array}{l}\text { - Increases social responses } \\
\text { and social influence [20] } \\
\text { - Helps social structuring } \\
\text { [30] } \\
\text { - Increases enjoyment and } \\
\text { persuasion [31, 41] } \\
\text { - Enhances } \\
\text { anthropomorphism [39, } \\
\text { 56] } \\
\text { - Enhances social presence } \\
\text { - Supports self efficacy [44] } \\
\text { - Supports self awareness } \\
\text { [45] }\end{array}$ & $\begin{array}{l}\text { Possible moderators } \\
\text { - Personal disposition [9, } \\
\text { 10,38] } \\
\text { - Expected task [43] } \\
\text { - Overdoing of cues [26] }\end{array}$ & $\begin{array}{l}\text { - Increases performance [28, } \\
\text { 26] } \\
\text { - Increases perceptual } \\
\text { bandwidth [49] } \\
\text { - Increases } \\
\text { anthropomorphism [57] }\end{array}$ & $\begin{array}{l}\text { - No effect on information } \\
\text { disclosure [45] } \\
\text { - Enhances loneliness and } \\
\text { preoccuppation [54] } \\
\text { - No effect on } \\
\text { anthropomorphism [56] } \\
\text { Possible moderators } \\
\text { - Personal disposition [54, } \\
28] \\
\text { - Expected task [5, 15, 8, } \\
\text { 11] }\end{array}$ \\
\hline \multicolumn{4}{|c|}{ Form and Function } \\
\hline \multicolumn{2}{|c|}{$\begin{array}{c}\text { Favorable } \\
3 \text { studies }\end{array}$} & \multicolumn{2}{|c|}{$\begin{array}{c}\text { Unfavorable } \\
7 \text { studies }\end{array}$} \\
\hline \multicolumn{2}{|c|}{$\begin{array}{l}\text { - Increases communication, efficiency, satisfaction [24] } \\
\text { - Increases human agency [26] } \\
\text { - Increases interest [47] }\end{array}$} & \multicolumn{2}{|c|}{$\begin{array}{l}\text { - Leads to feelings of eeriness and discomfort [7,25] } \\
\text { - No effect on social attribution [23] } \\
\text { - No effect on social usefullness of technology [24] } \\
\text { - Leads to classification difficulty between humans and } \\
\text { machines [25] } \\
\text { - Decreases intentional predictive behavior [29] } \\
\text { - No effect on performance [47] } \\
\text { - Increases difficulty in learning for ASD children [57] } \\
\text { Possible moderators } \\
\text { - Personal disposition [23] } \\
\text { - Expected task [57, 23] } \\
\text { - Attentional focus [29] } \\
\text { Overdoing of cues [7, 25] }\end{array}$} \\
\hline
\end{tabular}

\subsection{Anthropomorphic Dimensions}

User responses to AT help identify dimensions across which users anthropomorphize technology. Users anthropomorphize AT by attributing various human-like characteristics to them. These characteristics can be categorized to identify anthropomorphic dimensions. For example, people anthropomorphize technology with respect to physical similarity with human beings like having a face, body, and movement $[1,4,7]$, or emotionality like having empathy or sympathy [31]. Other anthropomorphic dimensions include intelligence that is embedded in natural language processing, conversational ability, and data-driven algorithms [6, 7, 18, 23, 29, 32, 19]. Sociality can be considered another dimension. It is reflected in attributions of social presence $[2,19,26$, $38,41,42,45]$, extraversion [6], engagement [6], human agency [18], friendliness [6, 19], social judgement [20], interaction satisfaction [24], enjoyment [31, 27] and social behaviors [54]. Functionality reflects attributions of human-like tasks such as guidance [18, 6, 47], advice [26], or providing recommendations [41, 42]. Personal qualities include human-like personality traits that people associate with technology. For example, confidence is attributed to avatars [1] and interface agents [44], and warmth is associated with robots [32]. Trust is the last dimension that can be identified in the literature [41, $5,9,26,39]$.

Form is associated with anthropomorphic dimensions of sociality $[20,30,41,42,6,19,31]$, physical similarity $[32,4,7]$, and trust $[41,9]$. Function seems to motivate attributions of sociality $[2,26,45,6]$, functionality $[26,41,42,18]$, and intelligence $[6,18]$. Table 2 lists anthropomorphic dimensions and related attributions.

Table 2: Anthropomorphic dimensions and related attributions

\begin{tabular}{|l|l|}
\hline $\begin{array}{l}\text { Anthropomorphic } \\
\text { Dimension }\end{array}$ & Attributions \\
\hline Physical Qualities & Similarity to self [30, 38, 19, 20, 44] \\
\hline Emotionality & Empathy, Sympathy [31] \\
\hline Intelligence & $\begin{array}{l}\text { Conversational ability [6, 23, 18]; } \\
\text { autonomy, interactivity [7, 18,]; } \\
\text { language [18, 23]; intentional } \\
\text { thinking [29] }\end{array}$ \\
\hline Sociality & $\begin{array}{l}\text { Social presence [2, 19, 26, 38, 41, 42, } \\
\text { 45]; extraversion [6]; engagement [6]; } \\
\text { human agency [18]; friendliness [6, } \\
19] ; \text { social judgement [20]; interaction } \\
\text { satisfaction [24]; enjoyment [31, 27]; } \\
\text { and social behaviors [54]. }\end{array}$ \\
\hline
\end{tabular}




\begin{tabular}{|l|l|}
\hline Functionality & $\begin{array}{l}\text { Guidance }[18,6,47] ; \text { advice [26]; or } \\
\text { providing recommendations [41, 42] }\end{array}$ \\
\hline Personal Qualities & $\begin{array}{l}\text { Confidence [1]; self-efficacy [44]; } \\
\text { warmth [32] }\end{array}$ \\
\hline Trust & Trust [9, 41]; credibility [5, 9, 26, 39] \\
\hline
\end{tabular}

\subsection{Moderators of AT influence on User Response}

Some studies provide explanations for the variation in user response to AT. Personal disposition seems to be a popular one. Studies highlighting personal disposition explain that anthropomorphism is a result of the user's tendency to anthropomorphize $[10,38,45]$. For example, lonely and preoccupied people tend to anthropomorphize more [54]. Personality traits like extraversion and agreeableness influence interpretation of human-like behavior, and hence the degree of anthropomorphism [6]. Difference in response is also a result of rationality [28] and core self-evaluations influence an individual's attributional response to AT [23]. Furthermore, one study suggests that participants with a low propensity to trust, distrust AT regardless of anthropomorphic form or function [9].

Anthropomorphism and related constructs also depend on the task expected to be performed by the machine [23]. For example, Burgoon et al. [5] show that human-AT interaction is more influential in decision-making tasks, while face-to-face interaction is preferred for interpersonal relationships. Similarly, humanness enhances human-like trust in human-like technology, meaning that people trust human-like technology to perform a human-like task [27]. Avatars can reduce transparency in interaction and reduce collaboration between individuals [43], so provided that the task is that of collaboration, face-toface interaction is preferred. Face-to-face interaction is also preferred for sensitive tasks like counseling for suicide [15]. Avatars can facilitate deception tasks in an online interaction because they can reduce the anxiety associated with deceptive behavior [17]. Several studies explain variation in user response by highlighting the mismatch between the machine's expected task and its human-like appearance. People are confused when presented with a robot with mechanical movements, but human-like form [7], and they also find semirealistic characters in movies eerie and difficult to identify as humans or machines [25].

Attentional focus also moderates the influence of AT on user response. Levin et al. [29] find that motivating users to focus on the robot's appearance can help people distinguish between robots and machines. Similarly, framing a chatbot as intelligent leads to positive evaluations of social presence [2].

Overdoing of human-like design cues is a moderator that motivates negative evaluation of AT. Kim and Sundar [26] find that overdoing of cues can stimulate users to deny mindless anthropomorphism. Making semirealistic characteristics [25], and adding smooth movement to a body of human-like robot [7] can lead to negative evaluations of the technology. Table 3 presents a summary of moderators as well as their influence on user response.

\section{Table 3. Moderators and their effect on user response}

\begin{tabular}{|c|c|}
\hline Moderator & Effect on Response \\
\hline Personal disposition & $\begin{array}{l}\text { - Extraversion and agreeableness traits of users influence behavior interpretation of technology [6] } \\
\text { - Participants with a low propensity to trust, distrust AT regardless of design [9] } \\
\text { - Anthropomorphism reflects individual difference in the tendency to anthropomorphize [10] } \\
\text { - Psychological variables influence a bot's ability to convey a persuasive sense of humanity [18] } \\
\text { - Beliefs about social roles and capabilities of technology influence the attributional response [23] } \\
\text { - Rationality effects the influence of flattery on performance and acceptability [28] } \\
\text { - Perceptions of anthropomorphism drive expectations of realism [38] } \\
\text { - Lonely/preoccupied people tend to anthropomorphize more [54] }\end{array}$ \\
\hline Expected task & $\begin{array}{l}\text { - HCI is influential in decision-making tasks, FtF is best for interpersonal relationships [5] } \\
\text { - Conflict between human-like form and mechanistic movements can surprise and confuse people [8] } \\
\text { - Computer positive/negative feedback has a strong impact on individual self-perceptions [11] } \\
\text { - Choice of avatar is determined by intention to deceive [15] } \\
\text { - Contextual variables influence a bot's ability to convey a persuasive sense of humanity [18] } \\
\text { - The nature of the technology/interface influences the individual's attributional response [23] } \\
\text { - Human-ness enhances human-like trust in human-like technology [27] } \\
\text { - Avatars negatively influence collaborative effectiveness [43] } \\
\text { - Learning with a social robot was harder for children with ASD than TD [57] }\end{array}$ \\
\hline Attentional focus & $\begin{array}{l}\text { - Human-like chatbots led to high perceived social presence only when framed to be intelligent [2] } \\
\text { - Attentional focus on how the robot looks makes the effect of anthropomorphism significant [29] }\end{array}$ \\
\hline Overdoing of cues & $\begin{array}{l}\text { - People found the most animated robot (body+smooth movement) to be eerie [7] } \\
\text { - Semi-realistic characters received eerie and classification difficulty ratings [25] } \\
\text { - Forced cues can stimulate participants to deny mindless anthropomorphic responses [26] }\end{array}$ \\
\hline
\end{tabular}




\subsection{Theoretical Perspectives}

The Computers as Social Actors paradigm (CASA), MAIN model, and literature on heuristic information processing, present user response as a mindless attributional response to AT. According to CASA, simple design cues in technology motivate consumers to attribute human-like characteristics to the machine $[1,2,5,30]$. The MAIN model that supports a heuristic approach to understand technology credibility, explains that anthropomorphic form leads to positive evaluations of technology [19, 26]. Human-like attribution, as a mindless heuristic response, leads to an increase in acceptance and utility [5, 42], performance [28], and enjoyment [42].

The literature on anthropomorphism and theories related to cognition explain user response to be an inductive reasoning process. These theoretical perspectives explain that users consciously accept or reject AT to meet psychological goals of decreasing cognitive strain [4], increasing engagement [6], enjoyment and persuasion [31], trust [43], and interest [47]. Social theories emphasize that humanlike familiarity with technology motivates trusting behavior [27, 41]. Human-likeness in design positively affects social presence, enjoyment, and intention to use [41, 42], as well as utility, selfefficacy, and interest, and anthropomorphism [44, 56].

Some theoretical perspectives explain the effect of moderators. Attribution theory, impression management theory, and self-presentation theory, for example, explain the influence of personal disposition $[23,38]$. Affordance theory explains the effect of expected task [27], and the uncanny valley hypothesis explains the influence of the overdoing of cues [25]. The three-factor theory of situational and motivational factors explains the effect of attentional focus on technology design [29].

\section{Discussion and Future Research}

Anthropomorphic design, its categories, user response, anthropomorphic dimensions, and moderators influencing user response to AT are the main findings of the review. We discuss these below with respect to future research directions.

\subsection{Anthropomorphic Design and User Response}

Human-like design facilitates technology acceptance mindlessly due to heuristic information processing, or mindfully as a result of cognitive reasoning. Counterintuitive evidence seems to be more of an outcome of mindful anthropomorphism than heuristic processing [26]. Kim and Sundar [26] explain that people deny their perception of humanlikeness of technology when probed about the human-like form or function. Perhaps this is why most studies explaining user response as a heuristic outcome provide a positive influence of humanlikeness in machines [5, 19, 26, 28, 42].

Anthropomorphic form supports heuristic processing of information. It is the first encounter of AT with the user, and influences first impressions [6]. The physical shape of the technology influences people's interaction with it [16], and overall, form seems to lead to increase in human-likeness and positive technology evaluations. The findings, backed by CASA and theories supporting heuristic processing of information, inform that form is an important aspect of human-like design in technology. It positively influences users' acceptance of technology depending on personal disposition and the task expected from the technology. The literature also suggests that the relationship between anthropomorphic form and positive technology evaluations is not linear, meaning that overdoing form may not lead to higher acceptance rates. The smallest of cues are enough to influence user response.

Anthropomorphic function seems to motivate mindful processing of information and is related to less favorable and more unfavorable user responses as compared to anthropomorphic form. This may suggest that while users are comfortable with a machine to appear as human, they may still expect it to retain its mechanistic functions. Reinforcing the automation bias literature, findings explain that human-like functionality may lead to decrease in machine-like trust that focuses on the machine's ability to be rational, efficient, and objective. Most studies explain counterintuitive responses to anthropomorphic function as a result of a mismatch between the design and user expectations. Surprisingly anthropomorphic function is associated with an increase in performance but that can be the result of personal disposition (low/high rationality), and human-like contexts like health.

Form and function, together, are associated with less favorable and more unfavorable user evaluations. Reiterating Mori's [33] uncanny valley hypothesis, the review suggests that incorporating both form and function in anthropomorphic design can lead to overdoing of human-like cues in 
machines and result in feelings of eeriness and discomfort.

Overall, the findings suggest that anthropomorphic form may just be enough to evoke anthropomorphism and respective positive anthropomorphic technology evaluations from users. At the same time, incorporation of both form and function may lead to withdrawal from and rejection of AT. While this is a safe conclusion, it is not a final one. Along with how much form and function is too less or too much, developers need to consider personal disposition, expected task, and attentional focus of the user when developing AT.

\subsection{Novel Approach and Future Research}

Anthropomorphism is a key construct explaining consumer reactions to human-likeness in technology. Most research in the domain of AT has focused on anthropomorphic design rather than user response. A better understanding of user response to AT can utilize a novel approach focusing on the exploration of anthropomorphic process and anthropomorphic dimensions.

Anthropomorphism, itself, is the attribution of human-like traits to technology. Variation in user response to AT suggests that anthropomorphism is more of a reasoning process that leads users to accept or reject AT. The cognitive reasoning that drives user response can be explored and understood with the help of anthropomorphic dimensions along which a machine is anthropomorphized. Perceptions about AT may change according to anthropomorphic dimensions. For example, if the dimension of anthropomorphism on which the user anthropomorphizes a robot is physical similarity, the response may be that of familiarity and acceptance [4], but if the anthropomorphic dimension is intelligence, the response may be strain due to privacy concerns [4]. A particular machine can motivate anthropomorphism in more than one dimensions based on the anthropomorphic design. The way design perspective should be utilized to explore the user perspective is to explore and identify the dimensions that users anthropomorphize AT on. These dimensions can change with respect to the influence or the extent of influence determined by human-like design. The interplay of anthropomorphic dimensions in the human mind for reasoning and decision-making can provide a cognitive explanation for variation in user response to AT. For instance, coactivation of physical similarity dimension from anthropomorphic form and intelligence dimension from anthropomorphic function may lead to a symbiotic response of acceptability, or a conflict response of strain. Moderators like user personality type, the task expected from AT, attentional focus and overdoing of cues will influence the application of a particular anthropomorphic dimension on AT.

Several considerations are highlighted in the literature that need empirical testing to evaluate the acceptance of AT. None of the studies make a clear distinction between anthropomorphic form and function to test the effectiveness of each separately. Researchers need to test variation in user response based on a clear identification of what constitutes anthropomorphic form and function, as well as the cognitive mechanism that drives user response for different kinds of dimensions and design stimulus. Researchers also need to determine the minimum and maximum thresholds for anthropomorphism and uncanny valley. Lastly, although the literature provides some insight about moderators that can lead to variation in user response, research is needed that empirically tests for the two kinds of design stimuli, and determines the degree to which they influence the cognitive application of anthropomorphic dimensions to AT.

\section{Conclusion}

This study is a step towards integrating some of the insights from extant research on human-likeness in technology and its acceptance with the user. This review examines studies published from 1998 to 2019 from the top and relevant journals in the IS field, focusing on intervention studies at an individual level of analysis. We find that while many human-like cues have been studied, a formal categorization is lacking to effectively anticipate user response to a particular kind of design intervention. We also find that user responses to AT can help with the identification of dimensions along which people anthropomorphize AT. Lastly, although the exact variables or process determining variation in user response to AT is unclear, it seems personal disposition, expected task from the interaction, attentional focus, and overdoing of cues may moderate user responses to AT.

\section{References}

[1] Al-Natour, S., Benbasat, I., \& Cenfetelli, R. T. (2006). The role of design characteristics in shaping perceptions of similarity: The case of online shopping assistants. Journal of the Association for Information Systems, 7(12), 34.

[2] Araujo, T. (2018). Living up to the chatbot hype: The influence of anthropomorphic design cues and communicative agency framing on conversational 
agent and company perceptions. Computers in Human Behavior, 85, 183-189.

[3] Baumeister, R. F., \& Leary, M. R. (1995). The need to belong: desire for interpersonal attachments as a fundamental human motivation. Psychological bulletin, 117(3), 497.

[4] Benlian, A., Klumpe, J., \& Hinz, O. (2019). Mitigating the intrusive effects of smart home assistants by using anthropomorphic design features: A multimethod investigation. Information Systems Journal.

[5] Burgoon, J. K., Bonito, J. A., Bengtsson, B., Cederberg, C., Lundeberg, M., \& Allspach, L. (2000). Interactivity in human-computer interaction: A study of credibility, understanding, and influence. Computers in human behavior, 16(6), 553574.

[6] Cafaro, A., Vilhjálmsson, H. H., \& Bickmore, T. (2016). First Impressions in Human--Agent Virtual Encounters. ACM Transactions on Computer-Human Interaction (TOCHI), 23(4), 24.

[7] Castro-González, Á., Admoni, H., \& Scassellati, B. (2016). Effects of form and motion on judgments of social robots' animacy, likability, trustworthiness and unpleasantness. International Journal of HumanComputer Studies, 90, 27-38.

[8] Cowan, B. R., Branigan, H. P., Obregón, M., Bugis, E., \& Beale, R. (2015). Voice anthropomorphism, interlocutor modelling and alignment effects on syntactic choices in human- computer dialogue. International Journal of Human-Computer Studies, 83, 27-42.

[9] Cowell, A. J., \& Stanney, K. M. (2005). Manipulation of non-verbal interaction style and demographic embodiment to increase anthropomorphic computer character credibility. International journal of humancomputer studies, 62(2), 281-306.

[10] De Kleijn, R., van Es, L., Kachergis, G., \& Hommel, B. (2019). Anthropomorphization of artificial agents leads to fair and strategic, but not altruistic behavior. International Journal of Human-Computer Studies, 122, 168-173.

[11] De Laere, K. H., Lundgren, D. C., \& Howe, S. R. (1998). The electronic mirror: Human-computer interaction and change in self-appraisals. Computers in Human Behavior, 14(1), 43-59.

[12] De Visser, E. J., Monfort, S. S., McKendrick, R., Smith, M. A., McKnight, P. E., Krueger, F., \& Parasuraman, R. (2016). Almost human: Anthropomorphism increases trust resilience in cognitive agents. Journal of Experimental Psychology: Applied, 22(3), 331.

[13] Duffy, D. L. (2003). Internal and external factors which affect customer loyalty. Journal of consumer marketing.

[14] Epley, N., Waytz, A., \& Cacioppo, J. T. (2007). On seeing human: a three-factor theory of anthropomorphism. Psychological review, 114(4), 864

[15] Farzanfar, R., Frishkopf, S., Friedman, R., \& Ludena, K. (2007). Evaluating an automated mental health care system: making meaning of human-computer interaction. Computers in Human Behavior, 23(3), 1167-1182.

[16] Fink, J. (2012, October). Anthropomorphism and human likeness in the design of robots and humanrobot interaction. In International Conference on Social Robotics (pp. 199-208). Springer, Berlin, Heidelberg.

[17] Galanxhi, H., \& Nah, F. F. H. (2007). Deception in cyberspace: A comparison of text-only vs. avatarsupported medium. International journal of humancomputer studies, 65(9), 770-783.

[18] Gilbert, R. L., \& Forney, A. (2015). Can avatars pass the Turing test? Intelligent agent perception in a $3 \mathrm{D}$ virtual environment. International Journal of HumanComputer Studies, 73, 30-36.

[19] Go, E., \& Sundar, S. S. (2019). Humanizing chatbots: The effects of visual, identity and conversational cues on humanness perceptions. Computers in Human Behavior, 97, 304-316.

[20] Gong, L. (2008). How social is social responses to computers? The function of the degree of anthropomorphism in computer representations. Computers in Human Behavior, 24(4), 1494-1509.

[21] Guthrie, S. E., \& Guthrie, S. (1995). Faces in the clouds: A new theory of religion. Oxford University Press on Demand.2

[22] Higgins, E. T. (1996). The" self digest": selfknowledge serving self-regulatory functions. Journal of personality and social psychology, 71(6), 1062.

[23] Johnson, R. D., Marakas, G. M., \& Palmer, J. W. (2006). Differential social attributions toward computing technology: An empirical investigation. International Journal of HumanComputer Studies, 64(5), 446-460.

[24] Kang, S. H., \& Watt, J. H. (2013). The impact of avatar realism and anonymity on effective communication via mobile devices. Computers in Human Behavior, 29(3), 1169-1181.

[25] Kätsyri, J., Mäkäräinen, M., \& Takala, T. (2017). Testing the 'uncanny valley hypothesis in semirealistic computer-animated film characters: An empirical evaluation of natural film stimuli. International Journal of Human-Computer Studies, 97, 149-161.

[26] Kim, Y., \& Sundar, S. S. (2012). Anthropomorphism of computers: Is it mindful or mindless?. Computers in Human Behavior, 28(1), 241-250.

[27] Lankton, N. K., McKnight, D. H., \& Tripp, J. (2015). Technology, humanness, and trust: Rethinking trust in technology. Journal of the Association for Information Systems, 16(10), 1.

[28] Lee, E. J. (2010). The more humanlike, the better? How speech type and users' cognitive style affect social responses to computers. Computers in Human Behavior, 26(4), 665-672.

[29] Levin, D. T., Saylor, M. M., Killingsworth, S., Gordon, S., \& Kawamura, K. (2008). Predictions about the behavior of computers, robots, and people: Testing the scope of intentional theory of mind in adults. Manuscript submitted for publication. 
[30] Lortie, C. L., \& Guitton, M. J. (2011). Social organization in virtual settings depends on proximity to human visual aspect. Computers in Human 3Behavior, 27(3), 1258-1261.

[31] MacDorman, K. F. (2019). In the uncanny valley, transportation predicts narrative enjoyment more than empathy, but only for the tragic hero. Computers in Human Behavior, 94, 140-153.

[32] Mara, M., \& Appel, M. (2015). Effects of lateral head tilt on user perceptions of humanoid and android robots. Computers in Human Behavior, 44, 326-334.

[33] Mori, M. (1970). Bukimi no tani [the uncanny valley]. Energy, 7, 33-35.

[34] Mosier, K. L., Skitka, L. J., Heers, S., \& Burdick, M. (1998). Automation bias: Decision making and performance in high-tech cockpits. The International journal of aviation psychology, 8(1), 47-63

[35] Mourey, J. A., Olson, J. G., \& Yoon, C. (2017). Products as pals: Engaging with anthropomorphic products mitigates the effects of social exclusion. Journal of Consumer Research, 44(2), 414431.

[36] Nass, C., \& Moon, Y. (2000). Machines and mindlessness: Social responses to computers. Journal of social issues, 56(1), 81-103

[37] Nass, C., Steuer, J., \& Tauber, E. R. (1994, April). Computers are social actors. In Proceedings of the SIGCHI conference on Human factors in computing systems (pp. 72-78). ACM.

[38] Nowak, K. L. (2013). Choosing Buddy Icons that look like me or represent my personality: Using Buddy Icons for social presence. Computers in Human Behavior, 29(4), 1456-1464.

[39] Nowak, K. L., \& Rauh, C. (2008). Choose your "buddy icon" carefully: The influence of avatar androgyny, anthropomorphism and credibility in online interactions. Computers in Human Behavior, 24(4), 1473-1493.

[40] Olson, C. (2016). Just say it: The future of search is voice and personal digital assistants. Campaign. Retrieved on 20 March 2020, from https://www.campaignlive.co.uk/article/just-say-itfuture-search-voice-personal-digitalassistants/1392459

[41] Qiu, L., \& Benbasat, I. (2009). Evaluating anthropomorphic product recommendation agents: A social relationship perspective to designing information systems. Journal of Management Information Systems, 25(4), 145-182.

[42] Qiu, L., \& Benbasat, I. (2010). A study of demographic embodiments of product recommendation agents in electronic commerce. International Journal of Human-Computer Studies, 68(10), 669-688.

[43] Riedl, René, Peter NC Mohr, Peter H. Kenning, Fred D. Davis, and Hauke R. Heekeren. "Trusting humans and avatars: A brain imaging study based on evolution theory." Journal of Management Information Systems 30, no. 4 (2014): 83-114.

[44] Rosenberg-Kima, R. B., Baylor, A. L., Plant, E. A., \& Doerr, C. E. (2008). Interface agents as social models for female students: The effects of agent visual presence and appearance on female students' attitudes and beliefs. Computers in Human Behavior, 24(6), 2741-2756.

[45] Sah, Y. J., \& Peng, W. (2015). Effects of visual and linguistic anthropomorphic cues on social perception, self-awareness, and information disclosure in a health website. Computers in Human Behavior, 45, 392-401.

[46] Seeger, A. M., Pfeiffer, J., \& Heinzl, A. (2017, December). When do we need a human? Anthropomorphic design and trustworthiness of conversational agents. In Proceedings of the Sixteenth Annual Pre-ICIS Workshop on HCI Research in MIS, AISeL, Seoul, Korea (Vol. 10).

[47] Shiban, Y., Schelhorn, I., Jobst, V., Hörnlein, A., Puppe, F., Pauli, P., \& Mühlberger, A. (2015). The appearance effect: Influences of virtual agent features on performance and motivation. Computers in Human Behavior, 49, 5-11.

[48] Shneiderman, B. "Reflections on authoring, editing, and managing hypertext, The society of text: hypertext, hypermedia, and the social construction of information." (1989).

[49] Sreejesh, S., \& Anusree, M. R. (2017). Effects of cognition demand, mode of interactivity and brand anthropomorphism on gamers' brand attention and memory in advergames. Computers in Human Behavior, 70, 575-588.

[50] Stebbins, S. (1993). Anthropomorphism. Philosophical studies, 69(2), 113-122.

[51] Straub, E. T. (2009). Understanding technology adoption: Theory and future directions for informal learning. Review of educational research, 79(2), 625649.

[52] The Guardian. (2018). How smart speakers stole the show from smartphones. The Guardian. Retrieved on 19 March 2020, from https://www.theguardian.com/technology/2018/jan/06 /how-smart-speakers-stole-the show-fromsmartphones

[53] Turkle, S. (2000, October 2). When toys are us. Forbes, pp. 213-214.

[54] Wang, W. (2017). Smartphones as social actors? Social dispositional factors in assessing anthropomorphism. Computers in Human Behavior, 68, 334-344.

[55] Webster, J., \& Watson, R. T. (2002). Analyzing the past to prepare for the future: Writing a literature review. MIS quarterly, xiii-xxiii.

[56] Yuan, L., \& Dennis, A. R. (2019). Acting Like Humans? Anthropomorphism and Consumer's Willingness to Pay in Electronic Commerce. Journal of Management Information Systems, 36(2), 450-477.

[57] Zhang, Y., Song, W., Tan, Z., Zhu, H., Wang, Y., Lam, C. M., Chen, J. (2019). Could social robots facilitate children with autism spectrum disorders in learning distrust and deception?. Computers in Human Behavior, 98 ,

$140-149$ 